\title{
Selective phosphodiesterase-5 inhibition reduces neointimal hyperplasia in rat carotid arteries after surgical endarterectomy
}

\author{
Kristóf Hirschberg, MD, ${ }^{\mathrm{a}, \mathrm{b}}$ Tamás Radovits, MD, PhD, ${ }^{\mathrm{a}, \mathrm{b}}$ Sivakkanan Loganathan, ${ }^{\mathrm{a}}$ László Entz, MD, PhD, ${ }^{\mathrm{b}}$ Carsten J. Beller, MD, ${ }^{\mathrm{a}}$ \\ Marie-Luise Gross, MD, ${ }^{\mathrm{c}}$ Peter Sandner, $\mathrm{PhD},{ }^{\mathrm{d}}$ Matthias Karck, MD, ${ }^{\mathrm{a}}$ and Gábor Szabó, MD, PhD ${ }^{\mathrm{a}}$
}

\begin{abstract}
Objective: Long-term results of surgical vessel reconstruction are compromised by restenosis caused by neointimal hyperplasia. Recent studies suggest that reduced cyclic guanosine monophosphate signaling is associated with neointima formation. In a rat model of endarterectomy, we investigated the effect of pharmacologic inhibition of cyclic guanosine monophosphate degradation on neointima formation by using the selective phosphodiesterase-5 inhibitor vardenafil.
\end{abstract}

\begin{abstract}
Methods: Carotid endarterectomy was performed in male Sprague-Dawley rats by means of incision of the right common carotid artery with removal of intima. Four groups were studied: unoperated control rats $(n=4)$, shamoperated rats $(n=9)$, control rats with endarterectomy $(n=9)$, or endarterectomized rats treated with vardenafil $(10 \mathrm{mg} / \mathrm{kg} /$ day $)$ postoperatively $(\mathrm{n}=9)$. After 3 weeks, vessel compartment areas were measured by means of conventional microscopy with hematoxylin and eosin staining. Immunohistochemical analysis was performed to confirm neointima formation and the local cyclic guanosine monophosphate content. Plasma levels of cyclic guanosine monophosphate were determined by means of enzyme immunoassay. Student's $t$ test was used for statistical evaluation.

Results: Immunohistochemical analysis demonstrated intensive staining for transforming growth factor $\beta 1$ and $\alpha$-smooth muscle actin in the control neointima. Vardenafil significantly reduced the stenosis grade $(24.64 \% \pm$ $7.46 \%$ vs $54.12 \% \pm 10.30 \%$ in the control group, $P<.05)$ and expression of transforming growth factor $\beta 1$, as well as $\alpha$-smooth muscle actin, in the neointima. The immunohistochemical score for cyclic guanosine monophosphate was higher in the treated neointima ( $4.80 \pm 0.76$ vs $2.84 \pm 0.40$ in the control group, $P<.05)$, and increased plasma cyclic guanosine monophosphate levels were found by means of enzyme immunoassay as well $(84.65 \pm 12.77 \mathrm{pmol} / \mathrm{mL}$ vs $43.50 \pm 3.30 \mathrm{pmol} / \mathrm{mL}$ in the control group, $P<.05)$.
\end{abstract}

Conclusions: Treatment with vardenafil can be considered a new possibility to prevent neointimal hyperplasia after endarterectomy.

Carotid endarterectomy is the standard treatment of severe carotid stenosis. ${ }^{1}$ Operative repair is not without potential complications, one of which is postoperative restenosis. Despite technical problems, the main cause of early restenosis after surgical vessel reconstruction is neointimal hyperplasia. Risk factors for early restenosis include alterations in the complement system, ${ }^{2}$ increased serum growth factor levels, ${ }^{3}$ or changes in the hemostatic factors. ${ }^{4}$ Ischemia-reperfusion injury and endothelial damage promote neointima formation. In contrast with early restenosis, late restenosis is due to the progression of primary atherosclerosis. ${ }^{5}$ Pathologically, the following processes

From the Departments of Cardiac Surgery ${ }^{\mathrm{a}}$ and Pathology, ${ }^{\mathrm{c}}$ University of Heidelberg, Heidelberg, Germany; the Department of Cardiovascular Surgery, ${ }^{\mathrm{b}}$ Semmelweis University, Budapest, Hungary; and Bayer HealthCare, ${ }^{\mathrm{d}}$ Wuppertal, Germany.

This work was partially supported by Bayer HealthCare, Wuppertal, Germany. Peter Sandner, $\mathrm{PhD}$, is an employee of Bayer HealthCare, Wuppertal, Germany.

Received for publication July 23, 2008; revisions received Sept 16, 2008; accepted for publication Oct 13, 2008

Address for reprints: Kristóf Hirschberg, MD, Experimental Laboratory of Cardiac Surgery, University of Heidelberg, Im Neuenheimer Feld 326, OG 2, 69120 Heidel-

berg, Germany (E-mail: hirschbergkristof@gmail.com).

J Thorac Cardiovasc Surg 2009;137:1508-14

$0022-5223 / \$ 36.00$

Copyright (C) 2009 by The American Association for Thoracic Surgery

doi:10.1016/j.jtcvs.2008.10.016 contribute to early restenosis: the migration of smooth muscle cells (SMCs) from the medial to the intimal layer, the proliferation of SMCs, the deposition of extracellular matrix material, and alterations in apoptosis of neointimal cells. ${ }^{6}$ Our previous studies showed that nitro-oxidative stress plays an important role in neointima formation after vascular injury, which could be effectively decreased by the inhibition of the peroxynitrite-poly (adenosine diphosphateribose) polymerase (PARP) pathway. ${ }^{7}$ In addition, evidence is growing that reduced nitric oxide (NO)-cyclic guanosine monophosphate (cGMP) signaling plays an important role in the pathogenesis of neointima formation, ${ }^{8}$ which could be prevented by local delivery of $\mathrm{NO}^{9}$ or by using a short-acting NO donor in the perivascular area of the injured rat carotid artery. ${ }^{10}$ Furthermore, neointimal proliferation could also be attenuated by endothelial NO synthase gene transfer in a rat model of balloon injury. ${ }^{11}$ Although there are several works that studied the effects of NO-cGMP signaling in the reduction of neointima formation through the administration of NO donors, to the best of our knowledge, there is little research on the effects of cGMP through its altered breakdown. A benzyl indazole derivative used in 2 different studies decreased neointimal hyperplasia; the drug has partial phosphodiesterase-5 inhibitory effects. ${ }^{12,13}$ Other 


\section{Abbreviations and Acronyms \\ cGMP = cyclic guanosine monophosphate \\ NO $=$ nitric oxide \\ PARP = peroxynitrite-poly (adenosine diphosphate-ribose) polymerase \\ $\mathrm{PKG}=$ protein kinase $\mathrm{G}$ \\ SMC $=$ smooth muscle cell \\ $\mathrm{TGF}=$ transforming growth factor \\ TUNEL $=$ terminal deoxynucleotidyl transferase- mediated dUTP-biotin nick end labeling}

phosphodiesterases have been shown to have beneficial effects on neointimal hyperplasia that are not selective for cGMP metabolism. ${ }^{14}$ Vardenafil is a novel phosphodiesterase-5 inhibitor drug that acts through the inhibition of cGMP degradation. This drug is already in clinical use for erectile dysfunction and pulmonary hypertension, but it has not been tested in cardiovascular diseases thus far or in the treatment of stenosis formation after intra-arterial injury. Because decreased cGMP signaling plays a central role in neointima formation leading to luminal stenosis, we investigated, in our rat model of carotid endarterectomy, whether neointimal hyperplasia can be prevented by the treatment with vardenafil. We also wanted to test the effect of vardenafil treatment on local and systematic cGMP levels. In addition, we analyzed whether phosphodiesterase- 5 inhibition affects neointimal proliferation and neointimal cell apoptosis after endarterectomy.

\section{MATERIALS AND METHODS \\ Rat Carotid Endarterectomy Model}

The protocol was approved by the Regional Ethical Committee for Laboratory Animal Use and conformed with the "Guide for the care and use of laboratory animals" published by the United States National Institutes of Health (publication no. 85-23, revised 1996). Eighteen male Sprague-Dawley rats (250-300 g body weight) underwent right carotid endarterectomy with removal of the intima, and 9 rats underwent a sham operation. After adequate anesthesia with an intraperitoneal injection of ketamine hydrochloride $(100 \mathrm{mg} / \mathrm{kg})$ and xylazine hydrochloride $(5 \mathrm{mg} / \mathrm{kg})$, the right common carotid artery was exposed by using a dissecting microscope through a midline cervical incision. A longitudinal arteriotomy was made with a corneal blade and extended to $6 \mathrm{~mm}$ with microscissors after clamping of the right common carotid artery. A sterile cotton-tipped applicator immersed in saponin $(0.1 \%)$ was rubbed on the inner vessel surface to denude the endothelium. This chemical skinning technique was used to preserve vascular smooth muscle function postoperatively. ${ }^{15,16}$ The arteriotomy was closed with a running 9-0 Ethilon monofilament nylon suture (Ethicon, Inc, Somerville, NJ). The superficial cervical muscles and skin were closed with running $4-0$ absorbable sutures. Animals were started postoperatively on a standard rat diet and provided with water ad libitum.

\section{Experimental Groups}

Animals were divided into 4 groups: (1) unoperated control rats $(n=4)$ for measurement of intact plasma; (2) sham-operated animals $(n=9)$ in which the carotid artery was not incised; (3) a control carotid endarterec- tomy group $(n=9)$ treated with the vehicle orally; and (4) the treatment group $(n=9)$, which received the phosphodiesterase-5 inhibitor vardenafil (10 $\mathrm{mg} / \mathrm{kg}$ daily, administered orally) dissolved in distilled water. This dose was drawn from recent literature reports showing efficacy of vardenafil in rat models. $^{17}$

\section{Perfusion Fixation Protocol}

After 21 days, the carotid arteries were perfusion fixed and harvested. First, the inferior vena cava was transected and the abdominal aorta was cannulated. Normal saline solution was infused at $100 \mathrm{~mm} \mathrm{Hg}$ until the vena cava effluent ran clear, and then a solution of $4 \%$ formaldehyde was infused at a constant pressure of $100 \mathrm{~mm} \mathrm{Hg}$ in an equal volume to the saline infusion (200 $\mathrm{mL})$ to complete the perfusion-fixation process.

\section{Histologic Analysis}

Morphometric analysis was performed in 3 hematoxylin and eosinstained cross-sections of each animal (proximal, mid, and distal regions of the operated vessel segment) by using computer-aided planimetry (Q-Win; Leica, Wetzlar, Germany). Luminal, intimal, and medial dimensions were computed by using the internal and external elastic laminae as delimeters. The percentage of stenosis was calculated by using the ratio between the neointimal area and the original luminal area. In addition, the neointimal/medial area ratio was calculated. From the 3 cross-sections, the mean was calculated for each animal, and then again the mean was calculated for the different experimental groups ( $\mathrm{n}=9$ animals per group), and these were compared between groups.

\section{Immunohistochemical Staining}

Immunohistochemical analysis was done in 3 representative cross-sections of each animal by using the avidin-biotin method. Local cGMP content was determined to test the phosphodiesterase-5 activity. The primary antibody used for this staining was rabbit polyclonal anti-cGMP antibody (AbD Serotec, Dusseldorf, Germany). We used transforming growth factor $\beta 1$ (TGF- $\beta 1$ ) staining to confirm proliferation activity. The TGF- $\beta$ system has been identified as a key defect of inhibitory systems, which regulates atherosclerosis and other injury-induced hyperplasias, such as restenosis. The primary antibody for TGF- $\beta 1$ was rabbit polyclonal immunoglobulin G (Santa Cruz Biotechnology, Santa Cruz, Calif). $\alpha$-Smooth muscle actin staining has been used to prove that neointimal cells originate from the medial layer of the injured artery. The primary antibody for $\alpha$-smooth muscle actin was mouse monoclonal immunoglobulin ( $\alpha$-Smooth Muscle Actin Immunohistology Kit; Sigma, Steinheim, Germany). The concentration that was optimal for staining was evaluated by testing different dilution series in a pilot study. The following dilutions of antibodies were used: 1:40 for TGF- $\beta 1$ and 1:1000 for cGMP. $\alpha$-Smooth muscle actin undiluted antibody solution was supplied in the immunohistology kit. ${ }^{18}$ Negative controls were performed by omitting the primary antibody. Immunohistochemical staining was evaluated by using the COLIM software package (Pictron Ltd, Budapest, Hungary). A digital camera was used to input microscopic pictures from a low-power $(16 \times-40 \times)$ magnification of the whole section and a high-power $(400 \times)$ examination of 5 adjacent fields. First, positively stained areas were separated from each other and from the background based on the intensity of different colors in the specimen. The colors were measured by using densitometric analysis and put in 4 color classes: 1 class for background staining and 3 classes for positively stained areas. On the basis of the measured intensity, the color classes were coupled with score values as follows: 0 , no positive staining; 1, weak staining; 2 , intermediate staining; and 3 , extensive staining. The program automatically measured the area of the objects in each class in each field, assigned an area score $(1, \leq 10 \%$ positive cells; $2,11 \%$ to $50 \%$ positive cells; $3,51 \%$ to $80 \%$ positive cells; $4,>80 \%$ positive cells), and calculated an average score for the whole picture (intensity score 
multiplied by area score, $0-12$ ). Finally, each specimen was characterized with the average of the 5 adjacent fields.

\section{Terminal Deoxynucleotidyl Transferase-Mediated dUTP-Biotin Nick End Labeling Assay}

Terminal deoxynucleotidyl transferase-mediated dUTP-biotin nick end labeling (TUNEL) is a common method for detecting DNA fragmentation that results from apoptosis or oxidative DNA damage. The cells with clear nuclear labeling were defined as TUNEL positive. These TUNEL-positive cells were counted in $1000 \mu \mathrm{m}^{2}$ of neointimal tissue segments and were compared between the control endarterectomized and treatment groups. The number of tissue sections in each group was the same as for the morphometric analysis. ${ }^{6}$

\section{Enzyme Immunoassay}

Blood samples were collected from each animal in the unoperated, control endarterectomized, and treatment groups. Plasma was separated and placed immediately in liquid nitrogen. cGMP concentrations were determined by using competitive enzyme immunoassay with a cGMP enzyme immunoassay kit (Amersham, Piscatway, NJ).

\section{Statistical Analysis}

Values are expressed as means \pm SEM. Statistical analysis was performed with the Origin 7 statistical software product (OriginLab, Northampton, Mass). Two group comparisons were determined by using the Student's $t$ test.

\section{RESULTS}

Effects of the Phosphodiesterase-5 Inhibition on Neointima Formation and on the Expression of TGF- $\beta 1$ and $\alpha$-Smooth Muscle Actin

Three weeks after in vivo endothelial denudation, concentric neointima was found in the control endarterectomized group, resulting in a $54.12 \%$ stenosis of the original luminal area (Figure 1). In the phosphodiesterase-5 inhibitor-treated group, significant reduction of neointima formation was observed. Stenosis was $24.64 \%$ in this group $(P<.05$, treatment group compared with control endarterectomy group). In addition, the neointimal/medial area ratio was calculated, which was found to be significantly reduced after phosphodiesterase-5 inhibition ( 0.50 vs 1.03 in the phosphodiesterase-5 inhibitor-treated group vs the control endarterectomy group, $P<.05$ ). In the sham and unoperated groups, normal morphologic structure was found with a single endothelial cell layer.

Neointimal cells originate from the medial layer of the injured de-endothelialized vessel by means of migration and proliferation of vascular SMCs. To confirm this, we detected $\alpha$-smooth muscle actin in the neointimas of the control and treated animals. Parallel to the extent of intimal
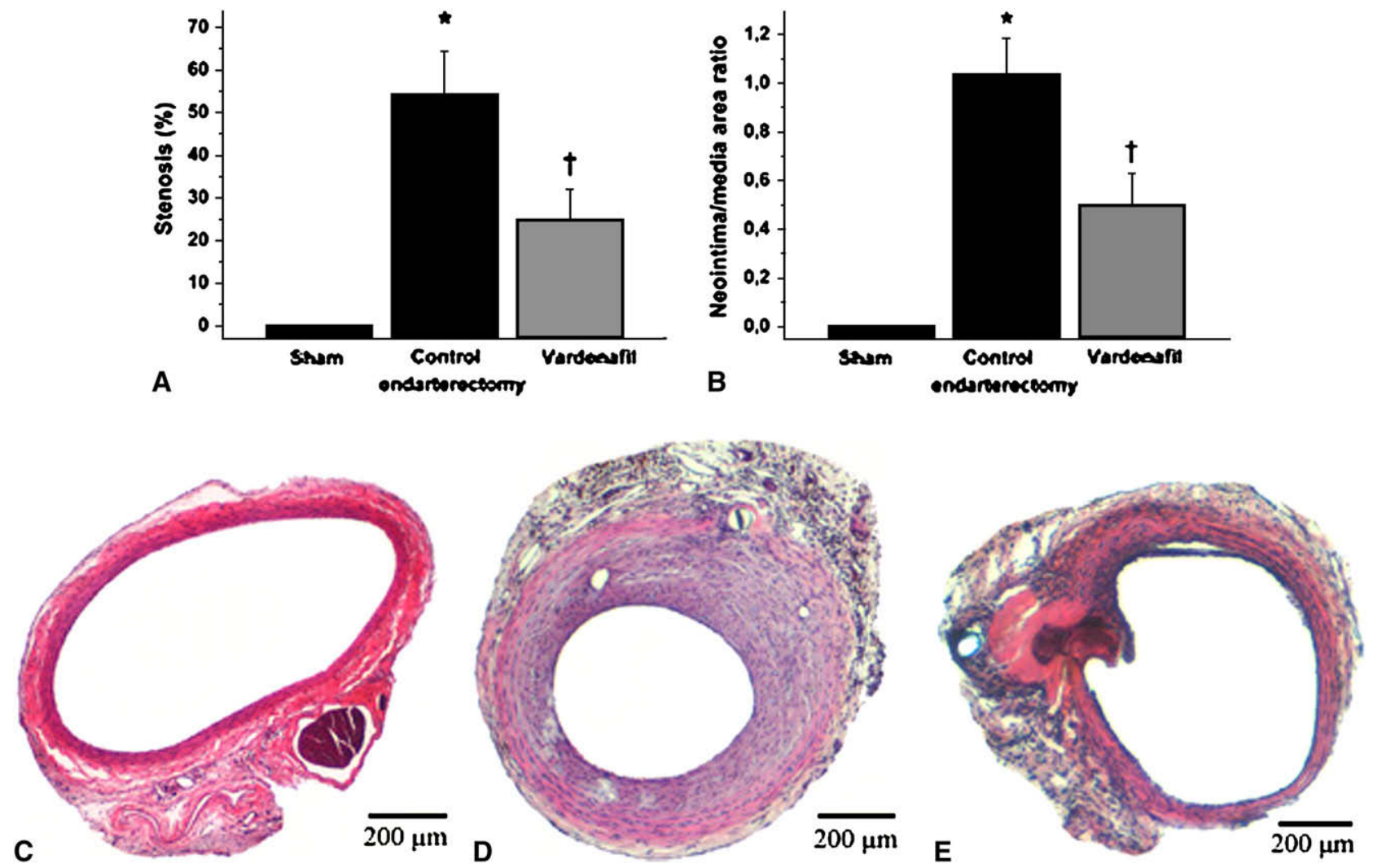

FIGURE 1. Morphometric results and representative histologic cross-sections from the different groups (hematoxylin and eosin staining). A, Percentage of stenosis (neointimal/original luminal area ratio). B, Neointimal/medial area ratio. C, Sham group. D, Control endarterectomy group with massive neointima proliferation. E, Significantly less neointima formation after treatment with vardenafil. $* P<.05$ vs sham operation; $\nmid P<.05$ vs control endarterectomy. 
thickening during neointima formation, significantly less immunoreactive $\alpha$-smooth muscle actin was found in the injured and treated vessels, whereas its levels were higher in the control group $(5.98 \pm 0.51$ vs $8.27 \pm 0.73$ in the control group, $P<.05$, Figure 2 ). In addition, we used TGF- $\beta 1$ immunostaining. Usually, marked TGF- $\beta 1$ staining can be seen in proliferating tissues; therefore it is a useful marker of the proliferation activity in the neointima. An extensive TGF- $\beta 1$ deposition was found in the control group, and the immunohistochemical score for TGF- $\beta 1$ was significantly less in the vardenafil-treated group (2.0 \pm 0.3 vs $5.82 \pm 1.09$ in the control group, $P<.05$ ).

\section{Effects of the Phosphodiesterase-5 Inhibition on Neointimal and Plasma cGMP Levels}

To confirm that the effect of vardenafil on neointima formation was related to the increase in cGMP levels seen in our endarterectomy model, we determined neointimal cGMP content by means of immunohistochemistry, as well as by measuring circulating cGMP levels by means of enzyme immunoassay in deep-frozen plasma samples. As shown in Figure 2, immunoreactivity for cGMP was significantly higher in the neointimas of the vardenafil-treated group compared with those of the control endarterectomized group. Semiquantitative evaluation of all sections of both groups indicated a significantly higher score for the phosphodiesterase-5 inhibitor-treated group compared with the control group ( $4.80 \pm 0.76$ vs $2.84 \pm 0.40$ in the control group, $P<.05)$. The increased cGMP levels in the treatment group could be shown systematically as well. Plasma cGMP concentrations were almost twice as increased as in the control groups $(84.65 \pm 12.77 \mathrm{pmol} / \mathrm{mL}$ vs $43.50 \pm 3.30 \mathrm{pmol} /$ $\mathrm{mL}$ and $38.20 \pm 2.18$ in the control endarterectomy and unoperated control groups, respectively; $P<.05$; Figure 3 ).
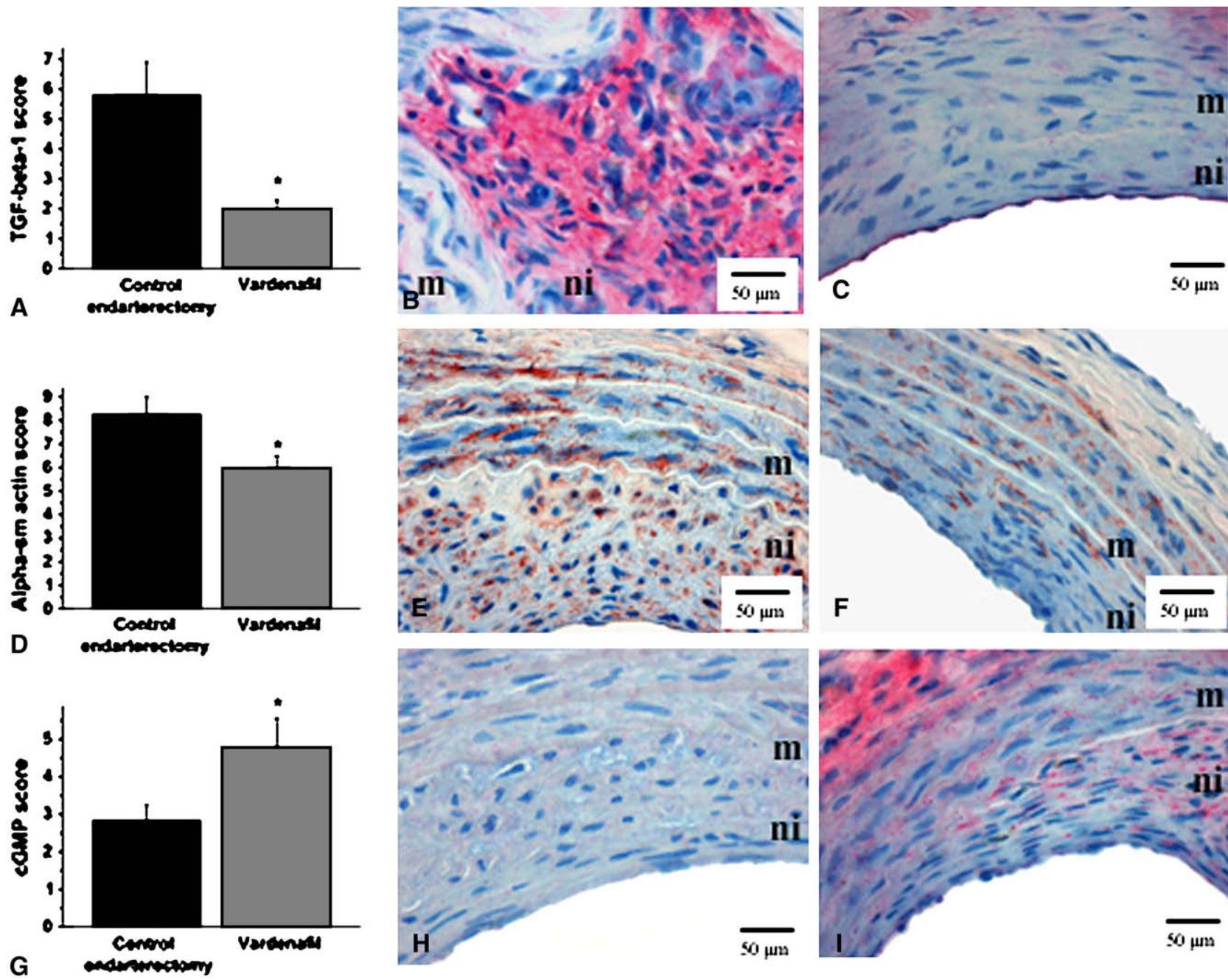

FIGURE 2. Representative photomicrographs (B-C, E-F, and $\mathrm{H}-\mathrm{I})$ and semiquantitative scoring $(\mathrm{A}, \mathrm{D}$, and $\mathrm{G})$ of immunohistochemical staining for transforming growth factor $\beta 1$ (TGF- $\beta 1$; red stain, A-C) and $\alpha$-smooth muscle actin (Alpha-sm actin; brown stain, D-F) and for cyclic guanosine monophosphate $(c G M P$; red stain) in the neointima $(\mathrm{G}-\mathrm{I})$ are shown in the control endarterectomy group $(\mathrm{B}, \mathrm{E}$, and $\mathrm{H})$ and the vardenafil treatment group $(\mathrm{C}$, F, and $\mathrm{I})$. $m$, media; $n i$, neointima. $* P<.05$ vs control endarterectomy. 


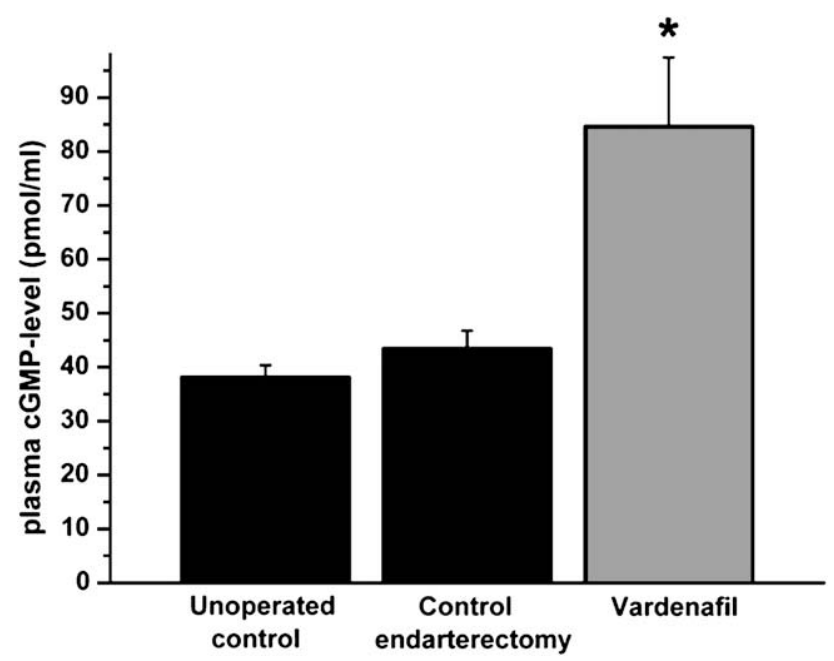

FIGURE 3. Cyclic guanosine monophosphate ( $(G M P)$ plasma concentrations (in picomoles per milliliter) measured by means of competitive enzyme immunoassay in the different groups. $* P<.05$ vs unoperated control and control endarterectomy.

On the other hand, there was no significant difference in plasma cGMP concentrations between the 2 control groups $(43.50 \pm 3.30$ in the control endarterectomy group vs $38.20 \pm 2.18$ in the unoperated control group).

\section{Effects of the Phosphodiesterase-5 Inhibition on Apoptosis of Neointimal Cells}

To test a possible contribution of apoptosis to the decrease of neointimal hyperplasia after treatment with vardenafil, we performed the TUNEL assay on each section from both groups. As shown in Figure 4, we did not find a significant difference in the apoptotic cell counts in the same unit (1000 $\left.\mu \mathrm{m}^{2}\right)$ of the control and treated neointimas $(4.23 \pm 0.43 \mathrm{vs}$ $4.44 \pm 0.64$ in the control group).

\section{DISCUSSION}

Recent studies show that reduced cGMP signaling is associated with neointimal proliferation, which is the main cause of restenosis after endarterectomy. ${ }^{8}$ It has also been shown that an NO donor can prevent neointimal hyperplasia in a rat carotid artery injury model, as well as in a porcine coronary injury model. ${ }^{9,10}$ Additionally, neointima formation could be reduced by adenovirus-mediated transfer of the endothelial NO synthase gene in a rat model of balloon injury. ${ }^{11}$ To the best of our knowledge, it has not been tested whether the selective inhibition of phosphodiesterase-5, the enzyme which is responsible for cGMP degradation, would also be capable of preventing neointima formation after endarterectomy. Some non-cGMP-specific phosphodiesterases have been tested and showed beneficial effects on neointimal hyperplasia. ${ }^{14}$ The benzyl indazole derivative YC-1 also decreased neointimal hyperplasia; nevertheless, this

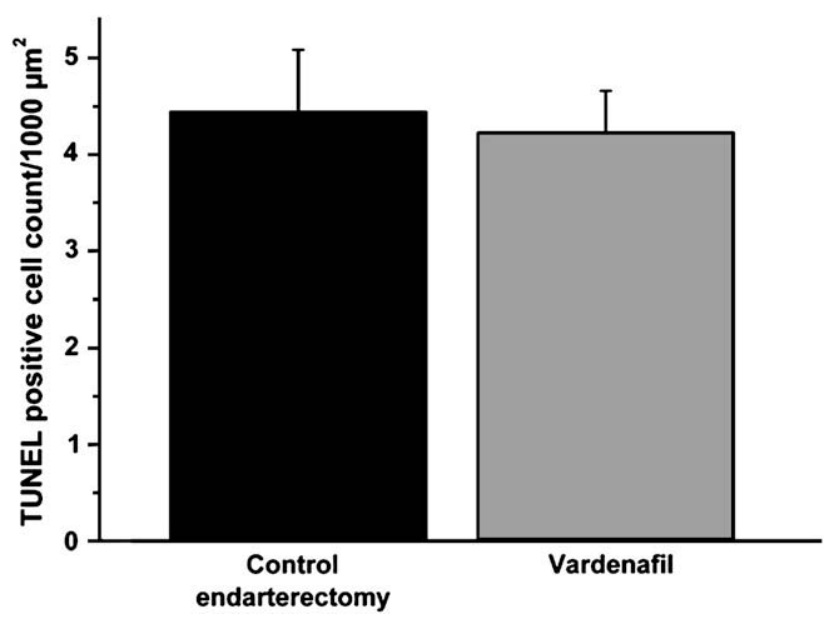

FIGURE 4. Terminal deoxynucleotidyl transferase-mediated dUTP-biotin nick end labeling (TUNEL)-positive cell count in $1000 \mu \mathrm{m}^{2}$ of neointima in the control endarterectomy and vardenafil groups.

drug has only a partial phosphodiesterase-5 inhibitory effect. ${ }^{12,13}$ The primary aim of our present study was to test the effectiveness of the novel selective phosphodiesterase-5 inhibitor vardenafil in a rat model of carotid endarterectomy. We previously showed, in the same rat carotid endarterectomy model, that 21 days after endothelial denudation, significant neointimal hyperplasia and ongoing neointima development is detectable; therefore we used the same timeframe in this study as well. ${ }^{15}$ The main results of the present study are that neointima formation and expression of different neointimal markers were attenuated by treatment with the phosphodiesterase-5 inhibitor vardenafil. Treatment with vardenafil significantly increased plasma cGMP levels, as well as neointimal cGMP content, as determined at the end of the 3-week follow-up period. Comparable neointimal reduction could be achieved in our previous studies by using the PARP inhibitor or the combination of brachytherapy and the PARP inhibitor. ${ }^{7,19}$

Endothelially derived NO is able to activate the soluble guanylate cyclase in vascular SMCs, which is responsible for cGMP synthesis. cGMP mediates its intracellular effects through activation of specific cGMP-dependent protein kinases (protein kinase $\mathrm{G}[\mathrm{PKG}]$ ). The main effects of cGMP, which could be involved in decreased neointima formation, are as follows: inhibition of migration and proliferation of vascular SMCs and alterations of oxidative and apoptotic signaling. ${ }^{20,21}$

A possible downstream signaling mechanism that contributes to the beneficial effects of phosphodiesterase- 5 inhibition on neointima formation acts through PKG, as was shown by Sinnaeve and colleagues ${ }^{22}$ in a PKG-overexpressed rat model. In another study by the same authors, the antiproliferative and antimigratory effects of soluble guanylate cyclase gene transfer after balloon injury in rats were demonstrated, which again confirms the role of 
cGMP signaling in the reduction of neointima formation. ${ }^{23}$ In connection with these results, Tulis and associates ${ }^{13}$ showed reduced postangioplasty stenosis after enhanced cGMP signaling by using a benzyl indazole derivate (YC-1) that can stimulate soluble guanylate cyclase (sGC) in vascular endothelium and SMCs. The benzyl indazole derivate used in this study has, in addition, a phosphodiesterase-5inhibiting secondary effect as well. Liu and coworkers ${ }^{12}$ showed similar results on neointimal hyperplasia using YC-1. Several mechanisms for the potent protective actions of vardenafil on neointima formation can be suggested based on results from in vitro studies. Yu and colleagues ${ }^{21}$ showed an inhibition of DNA synthesis associated with diminution in mitogen-activated protein kinase levels after enhanced cGMP signaling. Other work showed cGMP-induced inhibition in anti-mitogen cyclin-dependent kinase activity and cyclin D1 expression, leading to the suppression of cell cycle in vascular cells. ${ }^{24}$

An interesting new finding of our study is a significant reduction of TGF- $\beta 1$ immunoreactivity in the neointima after treatment with the phosphodiesterase-5 inhibitor vardenafil. It has been shown in several studies that the TGF- $\beta$ system contributes to neointimal proliferation and that neointimal hyperplasia could be suppressed by using TGF- $\beta$ antibody. ${ }^{25,26}$ TGF- $\beta 1$ is overexpressed in fibroproliferative vascular lesions, allowing a slow but uncontrolled growth while overproducing extracellular matrix components. In addition, Saura and coworkers ${ }^{27}$ showed that endothelial cells treated with an NO donor exhibited a decreased response to TGF- $\beta$, resulting in a downregulation of TGF- $\beta$ target genes. ${ }^{28}$ Taking these findings together with our present results, the following explanation can be given for the linkage between cGMP and TGF- $\beta 1$ signaling during neointima formation: NO decreases TGF- $\beta 1$ signaling through increases in cGMP levels, which finally leads to reduced vascular SMC proliferation. In our opinion the same linkage is present in the phosphodiesterase-5 inhibitor-treated neointima because treatment with vardenafil leads to an increased cGMP signaling similar to the effect of NO. The observed reduction in TGF- $\beta 1$ levels after treatment with vardenafil in our study might be a primary consequence of phosphodiesterase- 5 inhibition because of interrupted cytokine production rather than a secondary phenomenon. Nevertheless, we have no direct evidence in the present study or in the literature that would support this hypothesis. In addition to the decreased TGF- $\beta 1$ immunoreactivity after treatment with vardenafil, we found decreased expression in $\alpha$-smooth muscle actin as well. Cell culture studies suggest that vascular SMC migration is attenuated by the NO-cGMP-PKG pathway. ${ }^{20,29}$ On the other hand, cGMP-increasing agents have been found to prevent actin polymerization and thereby decrease vascular cell migration. We can speculate that decreased $\alpha$-smooth muscle actin expression found in the treated neo- intima in our study might be due to decreased proliferation and migration.

Chiche and associates ${ }^{30}$ showed proapoptotic effects of the NO-cGMP pathway in cultured rat pulmonary artery SMCs after adenovirus-mediated gene transfer of cGMPdependent protein kinase. To test a possible contribution of apoptosis to the reduction of neointimal hyperplasia after treatment with phosphodiesterase-5 inhibitor, we performed the TUNEL assay. No effects were found in our in vivo model of restenosis, which leads us to the conclusion that attenuated neointima formation might be due to the decreased proliferation activity rather than to enhanced neointimal apoptosis. Nevertheless, we cannot exclude other mechanisms to be involved in the beneficial effects of phosphodiesterase-5 inhibition on neointimal hyperplasia. Vasodilatation or phosphorylation of protein kinases could also influence this process. Unfortunately, we do not have any direct evidence regarding this issue in our present study; further studies are necessary to investigate these issues.

\section{Limitations of the Study}

The carotid endarterectomy model used in this study does not resemble the complex situation of a severely diseased atherosclerotic artery in a patient. However, the native rat carotid artery is an established model of intimal hyperplasia. ${ }^{15}$ In addition, it has to be noted that animal models of atherosclerosis also lack direct comparability with the human situation. Even knockout models have pathophysiologic and phenotypic differences regarding plaque cause and morphology. However, further studies with animal models of atherosclerosis are warranted in the future to address this issue.

\section{CONCLUSION}

Treatment with the selective phosphodiesterase-5 inhibitor vardenafil significantly suppressed neointimal hyperplasia after surgical endarterectomy in a rat model. These results suggest a potential therapeutic role of vardenafil in preventing neointima formation and restenosis after endarterectomy.

The expert technical assistance of H. Ziebart and G. Piecha is gratefully acknowledged.

\section{References}

1. North American Symptomatic Carotid Endarterectomy Trial Collaborators. Beneficial effect of carotid endarterectomy in symptomatic patients with high-grade carotid stenosis. N Engl J Med. 1991;325:445-53.

2. Szeplaki G, Hirschberg K, Gombos T, Varga L, Prohaszka Z, Dosa E, et al. Early complement activation follows eversion carotid endarterectomy and correlates with the time of clamping of the carotid artery. Mol Immunol. 2008;11:3289-94.

3. Szabo A, Laki J, Madsen HO, Dosa E, Prohaszka Z, Rugonfalvi-Kiss S, et al. Early rise in serum VEGF and PDGF levels predisposes patients with a normal MBL2 genotype to restenosis after eversion endarterectomy. Stroke. 2007;38:2247-53.

4. Dosa E, Szabo A, Prohaszka Z, Karadi I, Rugonfalvi-Kiss S, Apor A, et al. Changes in the plasma concentration of soluble thrombomodulin in patients with severe carotid artery stenosis after eversion endarterectomy. Inflamm Res. 2005;54:289-94. 
5. Hunter GC, Edgar J, Poth Memorial/W.L. Gore and Associates, Inc, Lectureship. The clinical and pathological spectrum of recurrent carotid stenosis. Am J Surg. 1997; 174:583-8.

6. Ohwada T, Ishibashi T, Yaoita H, Shindo J, Noji H, Ohkawara H, et al. Different contribution of apoptosis to the antiproliferative effects of L-arginine, enalapril and losartan on neointimal growth inhibition after balloon arterial injury. Circ J. 2002;66:965-71.

7. Beller CJ, Radovits T, Kosse J, Gero D, Szabo C, Szabo G. Activation of the peroxynitrite-poly(adenosine diphosphate-ribose) polymerase pathway during neointima proliferation: a new target to prevent restenosis after endarterectomy. J Vasc Surg. 2006;43:824-30.

8. Melichar VO, Behr-Roussel D, Zabel U, Uttenthal LO, Rodrigo J, Rupin A, et al. Reduced cGMP signaling associated with neointimal proliferation and vascular dysfunction in late-stage atherosclerosis. Proc Natl Acad Sci U S A. 2004;101:16671-6.

9. Yoon JH, Wu CJ, Homme J, Tuch RJ, Wolff RG, Topol EJ, et al. Local delivery of nitric oxide from an eluting stent to inhibit neointimal thickening in a porcine coronary injury model. Yonsei Med J. 2002;43:242-51.

10. Pearce CG, Najjar SF, Kapadia MR, Murar J, Eng J, Lyle B, et al. Beneficial effect of a short-acting NO donor for the prevention of neointimal hyperplasia. Free Radic Biol Med. 2008;44:73-81.

11. Janssens S, Flaherty D, Nong Z, Varenne O, van Pelt N, Haustermans C, et al. Human endothelial nitric oxide synthase gene transfer inhibits vascular smooth muscle cell proliferation and neointima formation after balloon injury in rats. Circulation. 1998;97:1274-81.

12. Liu YN, Pan SL, Peng CY, Guh JH, Huang DM, Chang YL, et al. YC-1 [3(5'-hydroxymethyl-2'-furyl)-1-benzyl indazole] inhibits neointima formation in balloon-injured rat carotid through suppression of expressions and activities of matrix metalloproteinases 2 and 9. J Pharmacol Exp Ther. 2006;316:35-41.

13. Tulis DA, Durante W, Peyton KJ, Chapman GB, Evans AJ, Schafer AI. YC-1, a benzyl indazole derivative, stimulates vascular cGMP and inhibits neointima formation. Biochem Biophys Res Commun. 2000;279:646-52.

14. Yamamoto K, Onoda K, Sawada Y, Fujinaga K, Imanaka-Yoshida K, Yoshida T, et al. Locally applied cilostazol suppresses neointimal hyperplasia and medial thickening in a vein graft model. Ann Thorac Cardiovasc Surg. 2007;13:322-30.

15. Beller CJ, Kosse J, Radovits T, Krempien R, Gross ML, Berger I, et al. Adjunct brachytherapy: a new concept to prevent intimal hyperplasia after surgical endarterectomy? Eur J Cardiothorac Surg. 2006;29:334-42.

16. Legan E, Sisson JA. Method to denude rat aortic endothelium with saponin for phosphoinositide analysis in vascular smooth muscle. J Pharmacol Methods. 1990;23:31-9.

17. Filippi S, Morelli A, Sandner P, Fibbi B, Mancina R, Marini M, et al. Characterization and functional role of androgen-dependent PDE5 activity in the bladder. Endocrinology. 2007;148:1019-29.

18. Ehsan A, Sommer F, Schmidt A, Klotz T, Koslowski J, Niggemann S, et al. Nitric oxide pathways in human bladder carcinoma. The distribution of nitric oxide synthases, soluble guanylyl cyclase, cyclic guanosine monophosphate, and nitrotyrosine. Cancer. 2002;95:2293-301.
19. Beller CJ, Kosse J, Radovits T, Gero D, Krempien R, Gross ML, et al. Poly(ADPribose) polymerase inhibition combined with irradiation: a dual treatment concept to prevent neointimal hyperplasia after endarterectomy. Int J Radiat Oncol Biol Phys. 2006;66:867-75.

20. Munzel T, Feil R, Mulsch A, Lohmann SM, Hofmann F, Walter U. Physiology and pathophysiology of vascular signaling controlled by guanosine $3^{\prime}, 5^{\prime}$-cyclic monophosphate-dependent protein kinase [corrected Circulation 2008;108:3165]. Circulation. 2003;108:2172-83.

21. Yu SM, Hung LM, Lin CC. cGMP-elevating agents suppress proliferation of vascular smooth muscle cells by inhibiting the activation of epidermal growth factor signaling pathway. Circulation. 1997;95:1269-77.

22. Sinnaeve P, Chiche JD, Gillijns H, Van Pelt N, Wirthlin D, Van De Werf F, et al. Overexpression of a constitutively active protein kinase $\mathrm{G}$ mutant reduces neointima formation and in-stent restenosis. Circulation. 2002;105: 2911-6.

23. Sinnaeve P, Chiche JD, Nong Z, Varenne O, Van Pelt N, Gillijns H, et al. Soluble guanylate cyclase alpha(1) and beta(1) gene transfer increases NO responsiveness and reduces neointima formation after balloon injury in rats via antiproliferative and antimigratory effects. Circ Res. 2001;88:103-9.

24. Fukumoto S, Koyama H, Hosoi M, Yamakawa K, Tanaka S, Morii H, et al. Distinct role of cAMP and cGMP in the cell cycle control of vascular smooth muscle cells: cGMP delays cell cycle transition through suppression of cyclin D1 and cyclin-dependent kinase 4 activation. Circ Res. 1999;85: 985-91.

25. Fu K, Corbley MJ, Sun L, Friedman JE, Shan F, Papadatos JL, et al. SM16, an orally active TGF-beta type I receptor inhibitor prevents myofibroblast induction and vascular fibrosis in the rat carotid injury model. Arterioscler Thromb Vasc Biol. 2008;28:665-71.

26. Wolf YG, Rasmussen LM, Ruoslahti E. Antibodies against transforming growth factor-beta 1 suppress intimal hyperplasia in a rat model. J Clin Invest. 1994;93: 1172-8.

27. Saura M, Zaragoza C, Herranz B, Griera M, Diez-Marques L, Rodriguez-Puyol D, et al. Nitric oxide regulates transforming growth factor-beta signaling in endothelial cells. Circ Res. 2005;97:1115-23.

28. Wang S, Wu X, Lincoln TM, Murphy-Ullrich JE. Expression of constitutively active cGMP-dependent protein kinase prevents glucose stimulation of thrombospondin 1 expression and TGF-beta activity. Diabetes. 2003;52: 2144-50.

29. Gurjar MV, Sharma RV, Bhalla RC. eNOS gene transfer inhibits smooth muscle cell migration and MMP-2 and MMP-9 activity. Arterioscler Thromb Vasc Biol. 1999; 19:2871-7.

30. Chiche JD, Schlutsmeyer SM, Bloch DB, de la Monte SM, Roberts JD Jr, Filippov G, et al. Adenovirus-mediated gene transfer of cGMP-dependent protein kinase increases the sensitivity of cultured vascular smooth muscle cells to the antiproliferative and pro-apoptotic effects of nitric oxide/cGMP. J Biol Chem. 1998;273:34263-71. 